\title{
Prevalence and Distribution of Molar Incisor Hypomineralization in children receiving dental care in Caracas Metropolitan Area, Venezuela
}

\author{
Mónica Rodríguez-Rodríguez', William Carrasco-Colmenares ' , Aghareed Ghanim², \\ Alfredo Natera', María Gabriela Acosta- Camargo ${ }^{3}$
}

1. Universidad Central de Venezuela, Facultad de Odontología, Caracas, Venezuela

2. University of Melbourne, Melbourne Dental School, Victoria, Australia

3. Universidad de Carabobo. Facultad de Odontología. Valencia, Venezuela

\begin{abstract}
Great variation has been reported in worldwide prevalence of Molar Incisor Hypomineralization (MIH) and Hypomineralized Second Primary Molar (HSPM). South America has the highest regional prevalence. The aim of this study was to determine the prevalence and distribution of MIH HSPM in 6- to 12-year-old children who received care at two dental healthcare services (public and private) in Caracas Metropolitan Area, Venezuela. A cross-sectional prospective study was conducted on 145 children, of whom 121 were selected in the stratified random sample. A calibrated examiner (Kappa $=0.878 / 0.831$ ) evaluated all patients following the MIH diagnosis criteria established by the European Academy of Paediatric Dentistry and using a valid and reliable instrument. Data were analyzed with a significance level of 5\%. Of the 121 children, 46.28\% (56) were male and
\end{abstract}

$53.72 \%$ (65) female, average age $8.83 \pm 1.61$. The prevalence of MIH/HSPM was $25.6 \% / 20 \%$. Both enamel defects were more prevalent in females ( $p$-value $=0.026 / 0.005)$. Severe MIH/HSPM was present in $21.8 \% / 31.2 \%$ of cases. Average number of affected teeth was $4.16 \pm 2.19 / 1.68 \pm 0.74$; and the condition was more frequent in upper molars $(67.7 \% / 51.4 \%)$. It was concluded that prevalence of MIH in 6- to 12-year-old Venezuelan children who received care in Caracas Metropolitan Area was higher than the previously estimated prevalence for South America, with predominance of mild affectation and more frequently occurring in upper molars.

Received: April 2021; Accepted July 2021.

Keywords: molar - incisor - prevalence - dental - children.

\section{Prevalencia y distribución de Hipomineralización Incisivo-Molar en niños atendidos en el Área Metropolitana de Caracas, Venezuela}

\begin{abstract}
RESUMEN
Una gran variabilidad ha sido reportada en la prevalencia mundial de Hipomineralización Incisivo-Molar (HIM) y de Hipomineralización del segundo molar primario (HSMP). América del Sur presenta la prevalencia regional más alta. El objetivo de este estudio fue determinar la prevalencia y distribución de HIM y HSMP en niños entre 6 y 12 años atendidos en dos servicios de atención odontológica (público y privado) en el Área Metropolitana de Caracas, Venezuela. Se realizó un estudio prospectivo transversal en 145 niños. Se seleccionaron 121 niños en la muestra aleatoria estratificada. Un examinador calibrado (Kappa =0,878/0,831) evaluó a todos los pacientes siguiendo los criterios de diagnóstico de HIM establecidos por la Academia Europea de Odontología Pediátrica y utilizando un instrumento válido y confiable. Los datos se analizaron con un nivel de significancia del 5\%. De los 121 niños, el 46,28\% (56)
\end{abstract}

eran varones y el 53,72\% (65) mujeres con una edad media de $8,83 \pm 1,61$. La prevalencia de HIM/HSMP fue del $25,6 \% / 20 \%$. Ambos defectos del esmalte fueron más prevalentes en el grupo de niñas (valor de p-valor=0,026/0,005). La forma severa de HIM/HSMP estuvo presente en el 21,8\%/31,2\% de los casos. El promedio de número de dientes afectados por paciente fue de 4,16 $\pm 2,19 / 1,68 \pm 0,74$, siendo más frecuente en los molares superiores $(67,7 \% / 51,4 \%)$. Se concluyó que la prevalencia de HIM en niños venezolanos entre 6 y 12 años atendidos en el Área Metropolitana de Caracas fue superior a la prevalencia estimada previamente para Sudamérica, con predominio de afectación leve y más frecuente en molares superiores.

Palabras clave: molar - incisivo - prevalencia - dental - niños. 


\section{INTRODUCTION}

Molar Incisor Hypomineralization (MIH) is defined as a qualitative enamel developmental defect, presumably multifactorial in origin, characterized by demarcated opacities in one to four first permanent molars (FPMs), with or without involvement of permanent incisors (PI). In weak and porous FPMs, enamel rapidly progresses to post-eruptive breakdown (PEB) and caries ${ }^{1-3}$. Reports have shown that second primary molars (SPMs), mineralized at a similar time as the FPMs, can also be affected, with the condition defined as Hypomineralized Second Primary Molar (HSPM) ${ }^{4}$.

The global prevalence of MIH has been estimated as $11.24 \%$ to $14.2 \%$, despite the wide variability in prevalence studies that highlighted the need for standardized procedures and clinical assessment in order to reduce the heterogeneity. South America has been identified as the most affected region, with an estimated prevalence of $18 \% 0^{5,6}$. A systematic review and meta-regression analysis estimated $\mathrm{MIH}$ prevalent cases and incident cases in countries with no database. In Venezuela, prevalent cases were estimated at 4,120,887 in 2015, and incident cases were estimated at 86,782 in $2016^{7}$. In 2019, an MIH index was tested, providing confidence as a reliable and valid instrument for use in population-based studies, and it was recommended to determine MIH prevalence in epidemiological research ${ }^{8}$.

Only three studies have reported demarcated opacities in Venezuelan children (local school population and renal disease group) using DDE and mDDE Index from 2010 to $2018^{9-11}$. To our knowledge, no research has been conducted following standardized procedures and using EAPD criteria to determine MIH prevalence in Venezuela's pediatric population. The aim of this study was to determine the prevalence and distribution of MIH and HSPM in children who received dental care at two health services (one public and one private) in Caracas Metropolitan Area, Venezuela, and to compare the results with global epidemiological data.

\section{MATERIALS AND METHODS Study population}

A cross-sectional prospective study was conducted on 6- to 12-year-old children who received care at the School of Dentistry at Universidad Central de Venezuela or at a private dental care center, from May 2019 to March 2020. The classification of health sectors was based on a previous report ${ }^{12}$. The study was designed according to the checklist described in a systematic review of MIH prevalence studies in order to ensure proper quality ${ }^{5}$. Sample size was calculated using the formula: sample size (n) $=[\mathrm{Z} 2 \times P(1-P)] / \mathrm{d} 2$, where $\mathrm{Z}$ is the statistical level of confidence $[95 \%$ confidence interval $(\mathrm{CI})>$ $\mathrm{Z}=1.96]$, and $P$ is the expected prevalence and $\mathrm{d}$ the precision ${ }^{13}$, assuming $18 \%$ for expected prevalence and $7.5 \%$ as precision level. Twenty percent was added to the minimum sample to account for possible negative responses. The calculated sample size was 121 patients. All positive respondents were included in the total sample (n). A stratified randomized sample $\left(n_{1}\right)$ was calculated according to the size of each health sector group (positive respondents from the public and private sectors), using percentages and considering strong limitations in the previous randomized procedure, especially in the public sector. No official data is available about fluoride consumption level in salt or water.

The initial and final ethical approvals were secured from the Bioethics Committee, School of Dentistry, Universidad Central de Venezuela (CB-091-2019/ CB-133-2020). Parents or legal guardians signed informed consent before the clinical evaluation. Pursuant to national regulations, children also needed to assent to their participation in the study. Inclusion criteria were children seeking dental care (no general anesthesia or sedation required) with all first permanent molars fully erupted. Exclusion criteria were children using fixed orthodontic appliances, with special needs, disabilities, or contagious infectious diseases.

\section{Clinical assessment}

A valid and reliable instrument for MIH-index scoring was used for clinical evaluation ${ }^{8,14}$ (Table 1). Index teeth were FPMs, PI and SPMs.

All patients were examined while seated in a dental chair by a calibrated examiner, using a dental light source and a flat mirror number 5 . The examiner adhered to standard infection control protocol, using single vision lenses +2.5 . Subjects were positioned to receive maximum illumination. Before examination, all teeth were cleaned and dried with gauze. The evaluation of index teeth was initiated in the right maxillary region (Quadrant 1), followed by the left maxillary index teeth (Quadrant 2), then the 


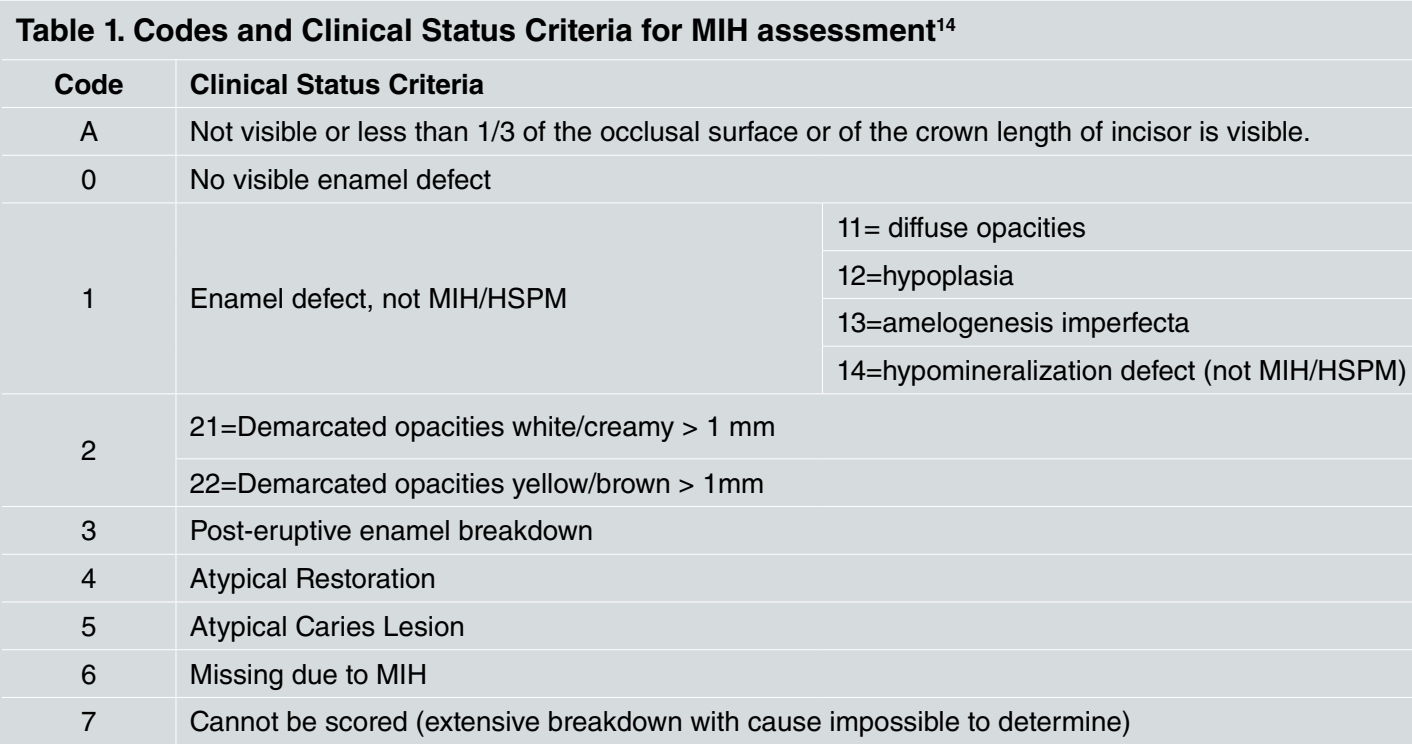

mandibular arch, beginning with the most posterior index tooth in the left quadrant (Quadrant 3), and finally moved around to the last index tooth in the right mandibular quadrant (Quadrant 4). A sequential code registration was carried out in a written form. Severity was classified as mild (Codes 21 and 22) or severe (Codes 3, 4, 5 and 6).

\section{Calibration exercise}

A pediatric dentist was calibrated in EAPD diagnosis criteria for the MIH index, using clinical photographs collected from patients who had previously been examined for the presence/absence of tooth developmental defects of enamel and following the $\mathrm{MIH}$ training manual for clinical field surveys and practice ${ }^{14}$. Three calibration sessions for clinical status were held. Intra-examiner reliability Kappa value was 0.878 and Inter-examiner reliability Kappa value was 0.831 .

\section{Statistical analyses}

Data were collected and tabulated using Microsoft Excel 2010 (Microsoft Corp., Washington, USA) and analyzed using Statistical Package for Social Sciences version 20 for Windows (SPSS Inc., Chicago, IL, USA) software. The MIH group included cases with codes 2, 3, 4, 5 or 6 in at least one FPM. The NOMIH group included cases without codes 2, 3, 4, 5 or 6 in at least one FPM. The prevalence of MIH/HSPM was calculated by frequencies, confidence interval (95\%). Descriptive statistics were used to calculate frequency of affectation in index teeth. The chi- square test was used for association between MIH or HSPM and sex. The odds ratio (OR) was calculated to quantify the risk of presenting $\mathrm{MIH}$ according to presence of HSPM. The HSPM group included cases with codes 2, 3, 4, 5 or 6 in at least one SPM. The NO-HSPM group included cases without codes $2,3,4,5$ or 6 in at least one SPM. Adjusted SPM samples were made according to dental age (for total and randomized stratified sample), cases with no possible evaluation of all SPMs were excluded from the HSPM group. Cases in the MIH group with at least one affected SPM were included, although in some cases it was not possible to evaluate all SPMs. To calculate the number of MIH-affected teeth, affected SPMs were not considered, affected PIs were included. To calculate the number of HSPMaffected teeth, FPMs affected were not considered. The Mann Whitney U-test was used to evaluate the association between number of affected teeth and sex. Severity was calculated with respect to the total cases included in MIH and HSPM groups and to the total number of affected teeth in the MIH and HSPM groups, respectively. For this research, in case of a tooth with severe and mild presentation on different surfaces, the most severe form was considered and tabulated. Four dental groups were included in the analyses of the most affected tooth: FPM group (first permanent molars group), UPI group (upper permanent incisor group), LPI (lower permanent incisor group), SPM group (second primary molar group). Percentages were calculated with respect to the number of teeth evaluated in each group. 


\section{RESULTS}

\section{Sample distribution, MIH/HSPM prevalence and Odds Ratio.}

One hundred and forty five 6- to 12-year-old children seeking dental care were invited and accepted to participate in this study. Three children were excluded according to selection criteria. The total sample $(\mathrm{n}=142)$ was distributed as follows: 80 children $(56.33 \%)$ from a private center and 62 children (43.67\%) from a public center. Of the total sample, 65 children (45.78\%) were male and 77 $(54.22 \%)$ female. Average age of the total sample was $8.85 \pm 1.63$ years. A randomized stratified sample was calculated using SPSS ${ }^{\circledR}$ program according to health sector group size and the minimum sample size previously determined $\left(n_{1}=121\right)$. Of the randomized stratified sample, 56 children (46.28\%) were male and $65(53.72 \%)$ female. Average age of the randomized stratified sample was $8.83 \pm 1.61$. MIH prevalence was $25.35 \%(n=36)$ (CI 95\%= $18.11 \%-32.59 \%$ ) for the total sample, and $25.62 \%$ $(n=31)(C I) 95 \%=17.73 \%-33.51 \%)$ for randomized stratified sample. Regarding health sector groups, $68(56 \%)$ children were examined in the private sector and $53(44 \%)$ children in the public sector for the randomized stratified sample. MIH prevalence was $30.88 \%$ in the private sector $(n=21)$ (CI $95 \%=$ $19.62 \%-42.15 \%$ ) and $18.87 \%$ in the public sector $(\mathrm{n}=10) \quad(\mathrm{CI} \quad 95 \%=7.98 \%-29.76 \%)$, Chi square $\mathrm{p}$-value $=0.133$ for randomized stratified sample.

One hundred and ten children were included in the SPM total sample: $47(42.73 \%)$ were male and 63 $(57.27 \%)$ female. Average of age was $8.38 \pm 1.44$ for the SPM total sample, and $8.35 \pm 1.41$ for the SPM randomized stratified sample. Ninety-four children were included in the SPM randomized stratified sample: 42 (44.68\%) were male and $52(55.32 \%)$ were female. HSPM prevalence was $18 \%(n=20)$
(CI $95 \%=11 \%-26 \%$ ) for the SPM total sample and $20 \%(n=19)(C I 95 \%=12 \%-28 \%)$ for the SPM randomized stratified sample. The co-occurrence of MIH and HSPM was $25.80 \%(n=8)$ in the stratified randomized sample. The Odds Ratio used to calculate the risk of presenting MIH according to presence of HSPM was 2.86 (CI 95\% = 1.04-7.87) for the SPM total sample and 2.48 (CI 95\%=0.867.15) for the SPM randomized stratified sample.

\section{Distribution in the MIH group}

The distribution of MIH prevalence according to sex was determined using the Chi square test with 5\% significance level (Table 2). Severity was determined according to the total cases included in the MIH group and the total number of affected teeth in the MIH group (Table 3). Mild cases represented $78.2 \%$ of the cases in the stratified randomized sample and $77.5 \%$ in total sample. The number of affected teeth in each dental group for both MIH samples was calculated (Table 4). The upper left FPM, central right UPI and lateral right LPI were the most affected teeth. For the stratified randomized sample, average affected upper/lower teeth was $67.7 \% / 58 \%$ for the FPM group. Average affected right/left teeth was $34.5 \% / 27.6 \%$ for the UPI group and $26.4 \% / 16 \%$ for the LPI group. Average affected teeth in the MIH group of the total sample was $4.19 \pm 2.17$ and $4.16 \pm$ 2.19 for stratified randomized sample. Girls had higher number of affected teeth than boys; U Mann Whitney $p$-value $=0.947$ for stratified randomized sample and $\mathrm{p}$-value $=1.000$ for total sample. Of the 31 children with MIH included

\section{Table 2. Distribution according to sex in MIH and NO-MIH groups}

\begin{tabular}{|c|c|c|c|c|c|}
\hline \multirow{3}{*}{ Variable } & \multicolumn{3}{|c|}{ Total sample $(n=142)$} & \multicolumn{2}{|c|}{$\mathrm{X}^{2}$} \\
\hline & \multicolumn{2}{|c|}{ MIH group } & \multicolumn{2}{|c|}{ NO-MIH group } & \multirow{2}{*}{$\mathrm{p}$-value } \\
\hline & $\mathrm{F}$ & $\%$ & $\mathrm{~F}$ & $\%$ & \\
\hline Male & 11 & 7.7 & 54 & 36.6 & \multirow{2}{*}{0.034} \\
\hline \multirow[t]{2}{*}{ Female } & 25 & 17.6 & 52 & 38 & \\
\hline & \multicolumn{4}{|c|}{ Stratified randomized sample $\left(n_{1}=121\right)$} & \\
\hline Male & 9 & 7.5 & 43 & 35.5 & \\
\hline Female & 22 & 18.2 & 47 & 38.8 & 0.026 \\
\hline
\end{tabular}


Table 3. Severity of MIH in samples for all cases and affected teeth

MIH Severity

Code 21: Opacities white/creamy $>1 \mathrm{~mm}$

Code 22: Opacities yellow/brown $>1 \mathrm{~mm}$

Code 3: Post-eruptive enamel breakdown

Code 4: Atypical Restoration

Code 5: Atypical Caries Lesion

Code 6: Missing due to MIH

\begin{tabular}{|c|}
\hline $\begin{array}{l}\text { For all cases } \\
\text { MIH group } \\
\text { Total sample }\end{array}$ \\
\hline
\end{tabular}

$83.3 \%$

$75 \%$

$25 \%$

$25 \%$

$11.1 \%$

$0 \%$

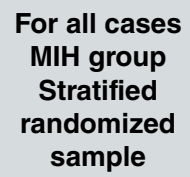

$45.7 \%$

$31.8 \%$

$10.6 \%$

$7.3 \%$

$4.6 \%$

$0 \%$
For affected

teeth

MIH group

Stratified

randomized

sample

$44.1 \%$

$34.1 \%$

$10.9 \%$

$6.2 \%$

$4.7 \%$

$0 \%$

Table 4. Distribution of MIH-affected teeth according to dental group and number of evaluated teeth

\begin{tabular}{|c|c|c|c|c|c|}
\hline Dental Group & Tooth & $\begin{array}{c}\text { Number of affected } \\
\text { teeth } \\
\text { Total sample } \\
\text { n (\%) }\end{array}$ & $\begin{array}{c}\text { Number of } \\
\text { evaluated teeth in } \\
\text { group } \\
\text { Total sample }\end{array}$ & $\begin{array}{c}\text { Number of affected } \\
\text { teeth } \\
\text { Stratified } \\
\text { randomized sample } \\
\text { n (\%) }\end{array}$ & $\begin{array}{c}\text { Number of } \\
\text { evaluated teeth in } \\
\text { group } \\
\text { Stratified } \\
\text { randomized sample }\end{array}$ \\
\hline \multirow{4}{*}{ FPM } & 16 & $23(63.8 \%)$ & 36 & $19(61.2 \%)$ & 31 \\
\hline & 26 & 27 (75\%) & 36 & $23(74.2 \%)$ & 31 \\
\hline & 36 & 25 (69.4\%) & 36 & $21(67.7 \%)$ & 31 \\
\hline & 46 & $16(44.4 \%)$ & 36 & $15(48.3 \%)$ & 31 \\
\hline \multirow{4}{*}{ UPI } & 11 & $18(54.5 \%)$ & 33 & $17(60.7 \%)$ & 28 \\
\hline & 12 & $5(19.2 \%)$ & 26 & $2(8.6 \%)$ & 23 \\
\hline & 21 & $14(42.4 \%)$ & 33 & $12(42.8 \%)$ & 28 \\
\hline & 22 & $6(22.2 \%)$ & 27 & $3(12.5 \%)$ & 24 \\
\hline \multirow{4}{*}{ LPI } & 31 & $3(8.3 \%)$ & 36 & $3(9.6 \%)$ & 31 \\
\hline & 32 & $4(11.4 \%)$ & 35 & $4(12.9 \%)$ & 31 \\
\hline & 41 & $5(13.8 \%)$ & 36 & $5(17.2 \%)$ & 29 \\
\hline & 42 & $5(15.6 \%)$ & 32 & $5(18.5 \%)$ & 27 \\
\hline
\end{tabular}

in stratified randomized sample, 5 (16.1\%) patients also presented hypomineralization defect (Code 14), $3(9.6 \%)$ patients showed diffuse opacities (Code 11) and only 1 patient (3.2\%) presented both (Codes 11 and 14).

\section{Distribution in the HSPM group}

The distribution of HSPM prevalence according to sex was determined using Chi square test results with 5\% significance (Table 5). Severity according to the total cases included in the HSPM group and to the total number of affected teeth in the HSPM group was determined (Table 6). Mild cases represented $69.8 \%$ of cases in the stratified randomized sample and $68.8 \%$ in the total sample. The number of affected teeth for both SPM samples was calculated. The upper right SPM was the most affected tooth (55.5\%). For the HSPM randomized sample, average affected upper/lower teeth was $51.4 \% / 45 \%$ for the HSPM group and $48.3 \% / 42.4 \%$ for the HSPM total sample

Average affected teeth in the HSPM group of the SPM total sample was $1.65 \pm 0.74$ and $1.68 \pm$ 0.74 for the SPM randomized sample. Girls had a higher number of affected teeth than boys; $U$ Mann Whitney test $p$-value $=0.903$ for stratified randomized sample and $p$-value $=0.816$ for the SPM total sample. 
Table 5. Distribution according to sex in HSPM and NO-HSPM groups

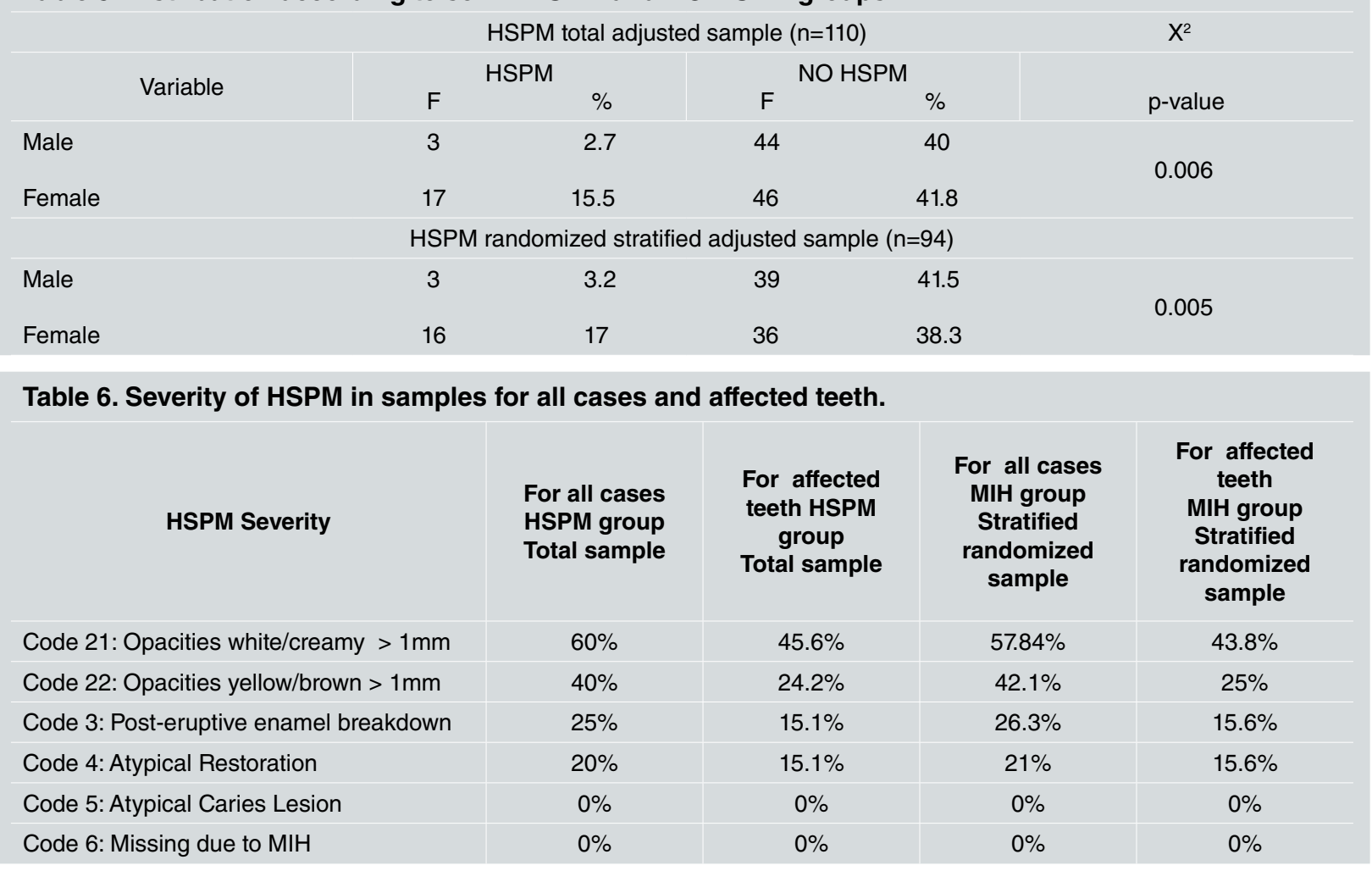

\section{DISCUSSION}

A prevalence of $\mathrm{MIH}$ of $25.62 \%$ was determined in a random sample of 6- to 12-year-old children who received dental care in Caracas Metropolitan Area. The number reported here is higher than the estimated prevalence for South America $(18 \%)^{6}$. It is very difficult to make comparisons of epidemiological interest between studies on MIH prevalence. Reports vary widely depending on population age, instrument, index used (DDE, mDDE, EAPD criteria), researcher calibration, evaluation technique and the setting, severity classification, research objectives and associated studies with other variables such as systemic conditions, etiological factors or dental caries.

Considering studies in which subjects were examined in a dental chair, MIH prevalence of $17.8 \%$ was found in a group of Spanish children using transillumination technique for dental surface evaluation ${ }^{15}$. A study conducted in private dental offices and university hospitals (specialized in pediatric dentistry) in eight regions of Japan reported a global prevalence of $19.8 \%{ }^{16}$. In Latin America, a study conducted in a dental chair setting on Argentinean children determined MIH prevalence of $15.9 \%$ with significant differences according to health sector (private sector: $24.40 \%$ and public sector: $6.4 \%)^{17}$. Similar results were reported for Uruguayan children with MIH prevalence of $12.3 \%$ (private sector: $26.99 \%$ and public sector: $7.13 \%)^{18}$. These authors suggested that differences between health sectors could be attributed to local factors related to access to dental healthcare.

The prevalence reported in the current study is higher, but similar to previously reported prevalence for private sectors in Argentina and Uruguay. Also in this report, MIH prevalence in the private sector is higher than in public sector, but without significant difference. These findings suggest that comorbidities and complications associated to MIH lead parents to seek private services, considering that retreatments are often required, and the great demand for public services due to the economic crisis in Venezuela.

Clinical assessment conducted at schools may result in underestimation of positive cases because of limited viewing conditions, such as patient and operator position, or inappropriate light source. Some studies on Latin American schoolchildren have reported MIH prevalence of $40.4 \%$ in Mexico, $40.2 \%-18.4 \%$ in Brazil and $15.8 \%$ in Chile ${ }^{19-22}$. 
Also, $12.3 \% \mathrm{MIH}$ prevalence was reported in schoolchildren in Brazil, but only opacities greater than $2 \mathrm{~mm}$ were recorded (outdoor setting) so there may have been underestimation ${ }^{23}$. Recently, Colombian schoolchildren were evaluated using portable dental equipment, with artificial light, and MIH prevalence was determined to be $11.2 \%{ }^{24}$. This wide variability in results and assessment highlights the need for standardized procedures, considering that opacities greater than $1 \mathrm{~mm}$ should be recorded ${ }^{14}$.

Regarding sex, significant difference in $\mathrm{MIH}$ prevalence has been found between Venezuelan girls and boys. Although systematic reviews had not determined this difference ${ }^{6,7}$, prevalence studies from Jordan and Iran have reported similar results ${ }^{25,26}$. In the current report, girls are more affected than boys, but the number of affected teeth does not differ significantly according to sex.

Clearly, MIH is more frequent in first permanent molars than in permanent incisors, with reports of molar involvement of $68.5 \%-58.9 \%$ in Argentina and $59.58 \%$ in a multicenter study in Argentina and Uruguay ${ }^{17,27}$. Those numbers are similar to our findings with an average of $67.7 \%$ for upper FPM and $56.45 \%$ for lower FPM. Small but significant differences have been previously reported between percentages of maxillary and mandibular affected teeth in Argentina ${ }^{28}$. Fortunately, the defect is mildly expressed in most cases, and severely affected teeth have been determined with values of $14.8 \%$ enamel breakdown and $9.1 \%$ atypical restorations in Brazilian schoolchildren ${ }^{23} ; 15 \%$ in Colombia (including cases of opacities with loss of structure, atypical restorations, and/or exodontia due to hypomineralization $)^{24}$, and $21.8 \%$ of loss of enamel in affected teeth in Argentina ${ }^{17}$. Findings in the current study also suggest that MIH can be found simultaneously with demarcated opacities in premolars and canines, and/or diffuse opacities compatible with dental fluorosis. The co-occurrence of MIH and dental fluorosis has also been reported recently in schoolchildren in Brazil ${ }^{29}$.

In this study, a $20 \%$ prevalence of HSPM was determined in a random and adjusted (to dental age) sample of 6- to 12-year-old children who received dental care in Caracas Metropolitan Area, with significant difference between sexes, girls being more affected than boys. The prevalence of
HSPM is highly variable worldwide and has been reported between $2.7 \%$ and $21.8 \%{ }^{30}$. The result found in the current study is within this range. The odds ratio determined in this study was 2.48 , lower than previously reported between 4.6 and $4.4^{4,31}$. However, it is still relevant for pediatric dentists, so that they can provide current information to parents or guardians and promote adequate follow-up.

Finally, the current study was conducted in dental chair setting, and prevalence observed in this setting could be higher than prevalence in the general population. MIH produces associated comorbidities such as dental hypersensitivity, caries lesions, frequent loss of restorations, aesthetic complaint and affectation of self-esteem and self-image, which are frequent reasons for consultation. Thus, these results must be properly interpreted and used as a reference for similar dental healthcare services.

\section{Limitations}

A recent publication has emphasized that the Venezuelan economic crisis has shattered the healthcare system and basic public services, threatening health in the country ${ }^{32}$. Strong limitations were faced during this investigation related to conditions in public service and general living conditions. Also, by national legislation, informed consent must be signed by a legal guardian and two witnesses, after the proper information has been provided by the researcher. It was therefore not considered feasible to perform a study in a school setting. Furthermore, the COVID-19 pandemic forced us to stop collecting data, though fortunately, the minimum sample size had been reached by March 2020 and the number of positive respondents enabled random selection.

\section{CONCLUSIONS}

The prevalence of MIH in 6- to 12-year-old Venezuelan children who received dental care in Caracas Metropolitan Area was higher than global prevalence and previously estimated prevalence for South America, with a predominance of mild affectation, and more frequent in upper molars. These results have major similarities with reports from Argentina, Uruguay and Brazil, and emphasize the significant number of children affected in Latin America. 


\section{ACKNOWLEDGMENTS}

The authors are grateful to those professors of Department of Orthodontic and Pediatric Dentistry who supported the research, and to parents and patients of the School of Dentistry of Central University of Venezuela who kindly agreed to participate in this study.

\section{DECLARATION OF CONFLICTING INTERESTS}

The authors declare no potential conflicts of interest regarding the research, authorship, and/or publication of this article

\section{REFERENCES}

1. Weerheijm KL, Jälevik B, Alaluusua S. Molar-Incisor Hypomineralisation. Caries Res 2001;35:390-391.

2. Silva MJ, Scurrah KJ, Craig JM, Manton DJ, Kilpatrick N. Etiology of molar incisor hypomineralization - A systematic review. Community Dent Oral Epidemiol 2016;44:342-353.

3. Garg N, Jain AK, Saha S, Singh J. Essentiality of Early Diagnosis of Molar Incisor Hypomineralization in Children and Review of its Clinical Presentation, Etiology and Management. Int J Clin Pediatr Dent 2012;5:190-196.

4. Elfrink MEC, ten Cate JM, Jaddoe VWV, Hoffman A, Moll A, Veerkamp JSJ. Deciduous Molar Hypomineralization and Molar Incisor Hypomineralization. $J$ Dent Res 2012;91:551-565.

5. Pentapati KC, Yeturu SK, Siddiq H. Systematic review and meta-analysis of the prevalence of molar-incisor hypomineralization. J Int Oral Health 2017;9:243-250.

6. Zhao D, Dong B, Yu D, Ren Q, Sun Y. The prevalence of molar incisor hypomineralization: evidence from 70 studies. Int J Paediatr Dent 2018;28:170-179.

7. Schwendicke F, Elhennawy K, Reda S, Bekes K, Manton DJ, Krois J. Global burden of molar incisor hypomineralization. J Dent 2018;68:10-18.

8. Ghanim A, Mariño R, Manton D. Validity and reproducibility testing of the Molar Incisor Hypomineralisation (MIH) Index. Int J Paediatr Dent 2019;29:6-13.

9. Medina Y, Agreda M, Simancas Y, Salas ME. Prevalencia de Fluorosis Dental, Opacidades e Hipoplasia del esmalte en niños en edad escolar. Acta Odontol Venez 2010;48:1-10. URL: https://www.actaodontologica.com/ediciones/2010/3/ art-11/

10. Agreda M, Simancas Y, Salas ME. Prevalencia de Fluorosis dental y anomalías de desarrollo del esmalte en los niños de la Escuela Bolivariana "Juan Ruiz Fajardo" del Estado Mérida, Venezuela. Acta Odontol Venez 2012;50:10. URL: https://www.actaodontologica.com/ediciones/2012/4/art12/

11. Acosta MG, Oliveros J, Coronel V, Tamy-Maury I. Association between oral finding and renal disease among pediatric patients in Venezuela. Rev ADM 2018;75:7179. URL: https://www.medigraphic.com/cgi-bin/new/ resumenI.cgi?IDARTICULO=79059

12. Bonvecchio A, Becerril-Montekio V, CarriedoLutzenkirchen Á, Landaeta-Jiménez MC. Sistema de salud de Venezuela. Salud Pública de México 2011;53:S275-S286. URL: https://www.scielosp.org/article/ssm/content/ raw/?resource_ssm_path=/media/assets/spm/v53s2/22.pdf

\section{FUNDING}

None

\section{CORRESPONDENCE}

MSc. Mónica Rodríguez Rodríguez

Av. Circunvalación del Sol. Centro Profesional Santa Paula

Santa Paula, Caracas. ZIP 1061

mrodriguezUCV.20@gmail.com

13. Elfrink MEC, Ghanim A, Manton DJ, Weerheijm KL. Standardised studies on Molar Incisor Hypomineralisation (MIH) and Hypomineralised Second Primary Molars (HSPM): a need. Eur Arch Paediatr Dent 2015;16:247-255.

14. Ghanim A, Silva MJ, Elfrink MEC, Lygidakis NA, Mariño RJ, Weerheijm KL, Manton DJ. Molar incisor hypomineralisation (MIH) training manual for clinical field surveys and practice. Eur Arch Paediatr Dent 2017;18: 225 242.

15. Martinez Gomez TP, Guinot JimenoF, Bellet Dalmau LJ, Giner Tarrida L. Prevalence of molar-incisor hypomineralisation observed using transillumination in a group of children from Barcelona (Spain). Int J Paediatr Dent 2012;22:100-109.

16. Saitoh M, Nakamura Y, Hanasaki M, Saitoh I, Murai Y, Kurashige Y, Fukumoto S, Asaka Y et al. Prevalence of molar incisor hypomineralization and regional differences throughout Japan. Environ Health Prev Med 2018;23:5561.

17. Biondi AM, Cortese SG, Martínez K, Ortolani AM, Sebelli PM, Ienco M, Paván VH, Mendel N et al. Prevalence of molar incisor hypomineralization in the city of Buenos Aires. Acta Odontol Latinoam 2011;24:81-85. URL: http:// www.scielo.org.ar/pdf/aol/v24n1/v24n1a13.pdf

18. López-Jordi M, Cortese SG, Álvarez L, Salveraglio I, Ortolani AM, Biondi AM. Comparison of the prevalence of molar incisor hypomineralization among children with different health care coverage in the cities of Buenos Aires (Argentina) and Montevideo (Uruguay) Salud Colect 2014;10:243-251. doi: 10.1590/S185182652014000200008

19. Villanueva Gutiérrez T, Barrera Ortega CC, Pérez Pérez N, García Pérez A. Impact of Molar Incisor Hypomineralization on Oral Health-Related Quality of Life in Mexican Schoolchildren. J Clinic Pediatr Dent 2019;43:324-330.

20. Soviero V, Haubek D, Trindade C, Da Matta T, Poulsen S. Prevalence and distribution of demarcated opacities and their sequelae in permanent 1st molars and incisors in 7 to 13-year-old Brazilian children. Acta Odontol Scan 2009;67:170-175.

21. Moura de Lima MD, Barroso Andrade MJ, Dantas-Neta NB, Andrade NS, Barbosa Teixeira RJ, Silva de Moura M, de Deus Moura Lde F. Epidemiologic Study of Molarincisor Hypomineralization in Schoolchildren in Northeastern Brazil. Pediatr Dent 2015; 37:513-519. 
22. Gambetta-Tessini K, Mariño R, Ghanim A, Calache $H$, Manton DJ. The impact of MIH/HSPM on the carious lesion severity of schoolchildren from Talca, Chile. Eur Arch Paediatr Dent 2019;20:417-423.

23. Jeremias F, Feltrini de Souza J, da Costa Silva CM, Loiola Cordeiro R C, Cilense Zuanon AC, Santos-Pinto L. Dental caries experience and molar incisor hypomineralization. Acta Odontol Scand 2013;71:870-876.

24. Mejía JD, Restrepo M, González S, Álvarez LG, SantosPinto L, Escobar A. Molar Incisor Hypomineralization in Colombia: Prevalence, Severity And Associated Risk Factors. J Clinic Pediatr Dent 2019;43:185-189.

25. Zawaideh FI, Al-Jundi SH, Al-Jaljoli MH. Molar incisor hypomineralisation: prevalence in Jordanian children and clinical characteristics. Eur Arch Paediatr Dent 2011;12:3136.

26. Ghanim A, Bagheri R, Golkari A, Manton D. Molar-incisor hypomineralisation: a prevalence study amongst primary schoolchildren of Shiraz, Iran. Eur Arch Paediatr Dent 2014; 15:75-82.

27. Biondi AM, López.Jordi M, Cortese SG, Alvarez L, Salveraglio I, Ortolani AM. Prevalence of molar-incisor hypomineralization $(\mathrm{MIH})$ in children seeking dental care at the Schools of Dentistry of the University of Buenos Aires
(Argentina) and University of la Republica (Uruguay). Acta Odontol Latinoam 2012;25:224-230. URL: http:// actaodontologicalat.com/wp-content/uploads/2017/07/12. pdf

28. Biondi AM, Córtese SG, Babino L, Toscano MA. Molar incisor hypomineralization: Analysis of asymmetry of lesions. Acta Odontol Latinoam 2019;32:44-48. URL: http://www.scielo.org.ar/pdf/aol/v32n1/v32n1a07.pdf

29. Cartaxo Fernandes I, Soares Forte FD, Correia Sampaio F. Molar-incisor hypomineralization (MIH), dental fluorosis, and caries in rural areas with different fluoride levels in the drinking water. Int J Paediatr Dent 2020;31:475-482.

30. Owen ML, GhanimA, Elsby D, Manton DJ. Hypomineralized second primary molars: prevalence, defect characteristics and relationship with dental caries in Melbourne preschool children. Aust Dent J 2018;63:72-80.

31. Garot E, Denis A, Delbos Y, Manton D, Silva M, Rouas P. Are hypomineralised lesions on second primary molars (HSPM) a predictive sign of molar incisor hypomineralisation (MIH)? A systematic review and a meta-analysis. J Dent 2018;72:8-13.

32. Page KR, Doocy S, Reyna Ganteaume F, Castro JS, Spiegel P, Beyrer C. Venezuela's public health crisis: a regional emergency. Lancet 2019;393:1254-1260. 